\title{
Arabic and English Consonants: A Phonetic and Phonological Investigation
}

\author{
Mohammed Shariq \\ College of Science and Arts, Methnab, Qassim University, Saudi Arabia \\ E-mail: Shariq7771@gmail.com
}

Doi:10.7575/aiac.alls.v.6n.6p.146

URL: http://dx.doi.org/10.7575/aiac.alls.v.6n.6p.146
Received: 18/07/2015

Accepted: 15/09/2015

\begin{abstract}
This paper is an attempt to investigate the actual pronunciation of the consonants of Arabic and English with the help of phonetic and phonological tools like manner of the articulation, point of articulation, and their distribution at different positions in Arabic and English words. A phonetic and phonological analysis of the consonants of Arabic and English can be useful in overcoming the hindrances that confront the Arab EFL learners. The larger aim is to bring about pedagogical changes that can go a long way in improving pronunciation and ensuring the occurrence of desirable learning outcomes.
\end{abstract}

Keywords: Phonetics, Phonology, Pronunciation, Arabic Consonants, English Consonants, Manner of articulation, Point of articulation

\section{Introduction}

Cannorn (1967) and Ekundare (1993) define phonetics as sounds which is the basis of human speech as an acoustic phenomenon. It has a source of vibration somewhere in the vocal apparatus. According to Varshney (1995), Phonetics is the scientific study of the production, transmission and reception of speech sounds. It studies the medium of spoken language. On the other hand, Phonology concerns itself with the evolution, analysis, arrangement and description of the phonemes or meaningful sounds of a language (Ramamurthi, 2004). Phonology, according to Simpson (1972), is the statement or description of the lingual stoically relevant suprasegmental features, the phonetic system, Allophones, their distribution and the phonological structure. Ekundare (1993) simply puts phonology as "The study of the properties of the sound system of a language which speakers have mastered or internalized by the time they are competent users of it".

However, the entire sound system works towards the production of what we know as language. Language has been variously defined. Some of these definitions are listed here:

$>$ 'Language is a system of conventional spoken or written symbols by means of which human beings, as members of a social group and participants in its culture, communicate.'-Encyclopedia Britannica

$>$ 'Language is the expression of ideas by means of speech sounds combined into words.'- Henry Sweet (an English phonetician and language scholar).

$>$ 'Speech is the representation of the experience of the mind.'-Aristotle (Greek philosopher).

$>$ 'A language is a system of arbitrary vocal symbols by means of which a social group cooperates.'-Bloch and Trager (American linguists).

$>$ 'Language is undoubtedly a kind of means of communication among human beings. It consists primarily of vocal sounds. It is articulatory, systematic, symbolic and arbitrary.'-Derbyshire

\section{Literature Review}

One of the very early EFL studies on Egyptian learners gives an enlightening insight into the problem area of suprasegmentals for Arabic speaking English learners. Richard Beym in English as a Foreign Language in Egypt (1956) has this to say about Arabic speaking learners of English: "In teaching Arabic speakers to speak English one must consider intonational patterns. The intonational pattern that Arabic speakers use in their own language are often carried over into English... This is due to the fact that some important phonological aspects of the foreign language has not been presented to the Arabic speakers".

Further, and more significantly for the current study, he says: "Spoken Arabic...has no gliding pitches except in the terminal syllable of an utterance. The continuum of pitch sequences in Arabic is not a smooth flow, one leading into the next, producing a jump like sequence. This Arabic phenomenon produces (when carried over) a choppy, sing song English. With rare exception, such supra-segmental phonemes of English are not taught...

A major phonetic stumbling block in teaching English to the Arabic speakers is the problem of avoiding nonpermissible variations in vowel quality. In spoken Arabic the emphatic consonants (sometimes called velarized or retroflex consonants) have a strong influence upon preceding or following vowels...In attempts to produce the vowel sound in "sear" when sating "sir". The cause of this coloration (a phonemic distinction in English) is that the English word is heard to begin with what is recognized by the Arabic speaker as the non-emphatic spirant consonant.

Numerous studies have been conducted ever since in different languages the world over to measure and analyse the interference of the mother tongue on English in L2 or EFL speakers. In a larger context, such studies enable the L2 or 
EFL teaching community to identify and check the areas of interference and bring the EFL speaker's language closer to that of the native speaker. In fact in the United States, where a Master's Degree is offered in TESOL, topics in Phonology represent important opportunities for preparing language teachers to meet the speech intelligibility needs of L2 learners. John M. Murphy (1997) aptly highlighted the significance of learning sound systems in an article based on a survey of these courses.

In an EFL study in Japan, Riney et al. (2000) studied Segmentals and Global Foreign Accent. They investigated the relationship between global foreign accent and a more discrete feature of pronunciation- the substitution of the Japanese flap $[r]$ for English liquids [r] and [1]. The principal finding was a strong negative correlation between percentages of Japanese flap substitutions and accent ratings. In simple words it meant that when speech samples where the English liquids were substituted by the Japanese flap were rated for accentedness, the outcome was not significant. The discussion, however, addressed debate over teaching segments versus supra-segments and related pedagogical priorities. In another article on modification of the sound of a word or morpheme when juxtaposed with another, especially in fluent speech, Elizabeth Zsiga (2011) presents the results of an acoustic study of nasal assimilation and gestural overlap at word boundaries in Korean and Korean-accented English. Twelve speakers of Seoul Korean recorded phrases containing obstruent\# nasal and obstruent\# obstruent sequences in both Korean and English. Nasalization of the wordfinal obstruent, predicted by the rules of Korean phonology, occurred in $93 \%$ of obstruent\# nasal sequences in Korean and in $32 \%$ of such sequences in Korean-accented English, a rate of application higher than that reported in most other studies of external sandhi alternations in nonnative speech. Acoustic analysis found categorical nasalization in the L1 Korean productions, but both categorical and gradient nasalization, along with a high degree of inter- and intra-speaker variation, in the L2 English productions.

\section{Speech sounds: A research problem}

Whereas for the layperson there are two classifications of speech sounds or phonemes of English: vowels and consonants literature on the subject classifies them into a larger number of categories. According to Trager and Smith as quoted by Varshney, there are forty five phonemes for English. These are:

9 simple vowels

3 semi vowels

21 consonants

4 stresses

4 pitches

1 plus juncture

3 terminal juncture In Arabic, however, the number of consonant phonemes or sounds is 28 and of vowel sounds is a mere 3 (or 6 if we also count all of the longer and shorter sounds). Further, the feature of length applies to both consonants and vowels in Arabic whereas it applies only to the vowel sounds in English. As opposed to English, Arabic is rich in three particular sounds, viz. uvular, pharyngeal and pharyngealized.

Speaking of historical linguistics, English and Arabic belong to two different language families. This may account for the diverseness of the two languages. English, much like German, Flemish, Dutch and Norwegian, belongs to the Germanic group of Indo European family of languages. Arabic is a member of the Afro Asiatic or Hamito Semitic family of languages: a family that flourished in north Africa and southwestern Asia. It shares the dias with Egyptian, Berber, Cushitic and Chad.

Given these facts, it is not surprising that English poses a major challenge for the average Arabic speaking learner. However, it is a challenge that can be overcome with identification of sound differences between the two languages.

\section{Articulators}

Articulators are those organs of speech which take part in the production of speech sound. We describe them in categories; active articulators (mobile articulators) like, tongue, lower lip etc. and passive articulators (immobile articulators) like- upper lip, teeth, hard palate, soft palate, uvula, pharynx, alveolar ridge etc.

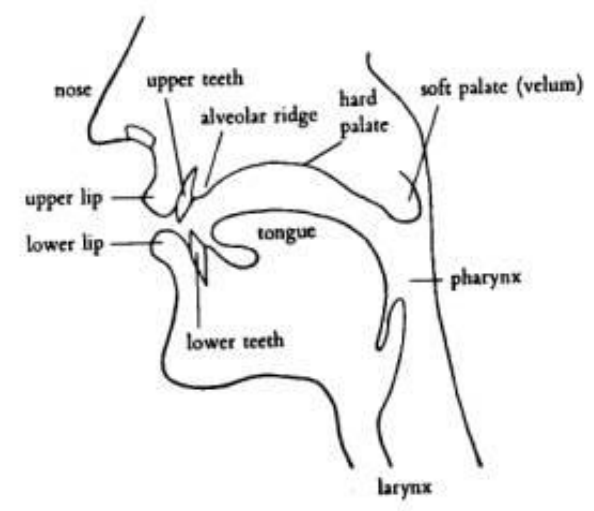

Figure 1. Articulators or organs of speech

(Peter Roach, 2009) 
THE INTERNATIONAL PHONETIC ALPHABET (revised to 2005)

CONSONANTS (PULMONIC)

(c) 2005 IPA

\begin{tabular}{|c|c|c|c|c|c|c|c|c|c|c|c|}
\hline & Bilabial & Labiodental & Dental & Alveolar & Postalveolar & Retroflex & Palatal & Velar & Uvular & Pharyngeal & Glottal \\
\hline Plosive & $\mathrm{p} \quad \mathrm{b}$ & & & $\mathrm{t} d$ & & $t d$ & $\mathrm{c} f$ & $\mathrm{k} \quad \mathrm{g}$ & $q \quad G$ & & $?$ \\
\hline Nasal & $\mathrm{m}$ & i1] & & 11 & & $\eta$ & $\mathrm{J}$ & 1] & $\mathrm{N}$ & & \\
\hline Trill & B & & & $r$ & & & & & $\mathrm{R}$ & & \\
\hline Tap or Flap & & r & & ؟ & & $\tau$ & & & & & \\
\hline Fricative & $\phi \beta$ & f $v$ & $\theta \partial$ & S Z & 3 & $\mathrm{~S} \quad \mathrm{Z}$ & ç $\dot{j}$ & $\begin{array}{ll}\mathrm{x} & \mathrm{y}\end{array}$ & $\chi$ в & h $\mathrm{I}$ & $\mathrm{h}$ h \\
\hline $\begin{array}{l}\text { Lateral } \\
\text { fricative }\end{array}$ & & & & 13 & & & & & & & \\
\hline Approximant & & $v$ & & I & & $t$ & $\mathrm{j}$ & U & & & \\
\hline $\begin{array}{l}\text { Lateral } \\
\text { approximant }\end{array}$ & & & & 1 & & $l$ & $\Lambda$ & $\mathrm{L}$ & & & \\
\hline
\end{tabular}

Where symbols appear in pairs, the one to the right represents a voiced consonant. Shaded areas denote articulations judged impossible.

Arabic consonants

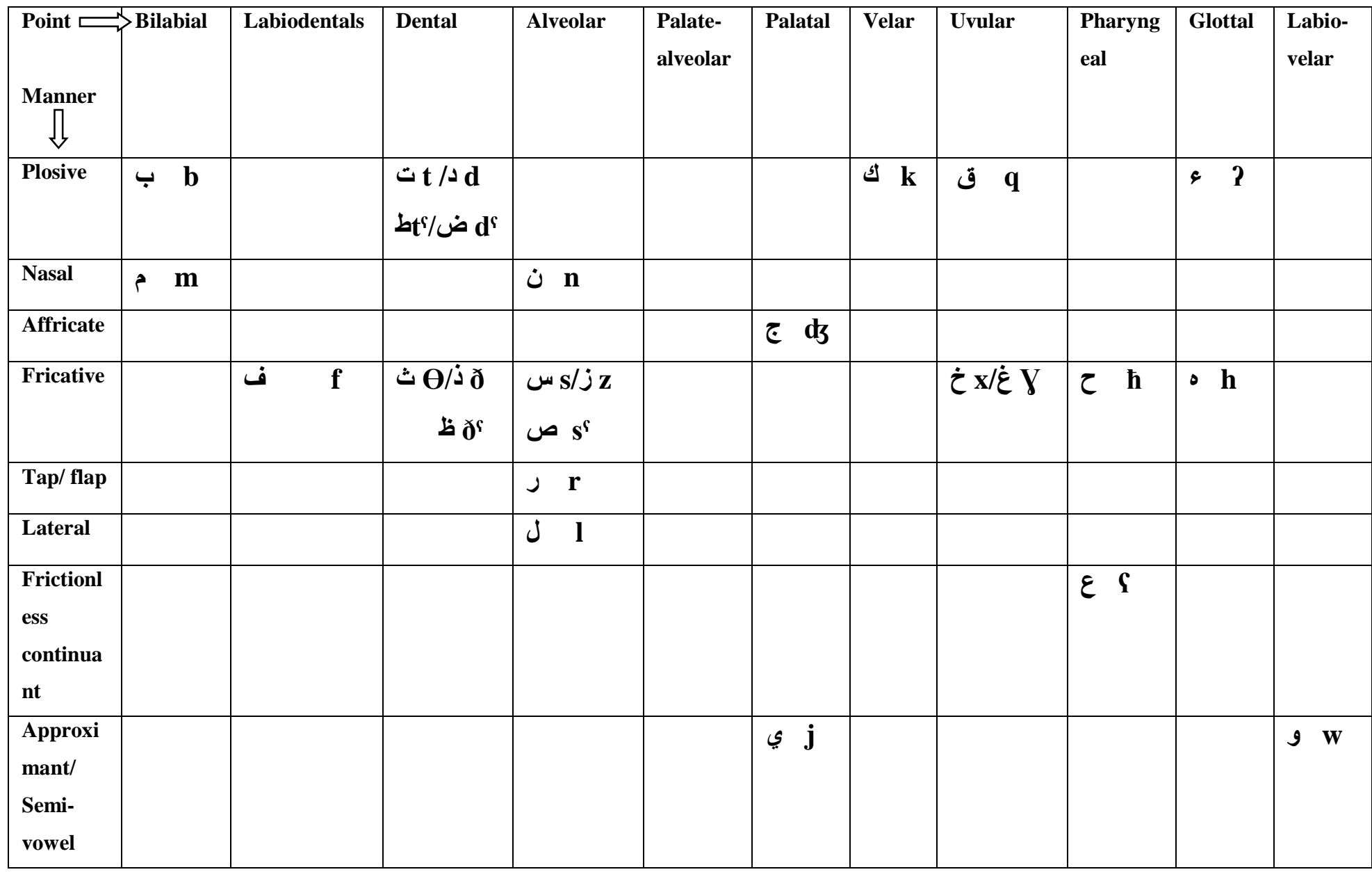

Figure 2. Arabic IPA Chart

Where symbols appear in pair, the one on the left represents a voiceless consonant and the one on the right represents a voiced consonant

\subsection{Place of articulation}

The place or point at which active articulator comes in contact or obstructs with passive articulator is referred as place or point of articulation.

\subsection{Manner of articulation}

The manner of articulation specifies the kind of closure or narrowing involved in the production of a sound. In other words, it specifies the kind of stricture (or constriction) involved in the articulation of a sound (Sethi \& Dhamija 2010). A comparison between Arabic and English consonants is discussed below: 


\section{Bilabial-plosives}

The lower lip comes in contact with the upper lip and produces an obstruction in the production of it. The articulators are the two lips in the production of bilabial consonants. The point of articulation is lips. On the other hand, it involves a stricture of complete closure. The air passage is closed at some point in the vocal tract which builds the air pressure behind the closure. Finally the closure the closure is suddenly eliminated with sudden release of air with some explosive noise. The result of manner of articulation is a plosive consonant.

Examples: The distribution of the consonant [ب] [b] is found in all the three positions in Arabic as in [ باسم ] [ ba:sım] 'happy, a male's name' at initial position, [ ابتداء ] [ Ibtada? ] 'beginning' at medial position and [ صعب ] [ s'aAb ] 'difficult' at final position. Similarly in English, bit [ bit ] at initial, lable [ lerbəl ] at medial and nib [ nib ] at final position is occurred.

The IPA Chart represents another bilabial plosive which is on the left side of $[b]$ that is [p]. Both [p] and [b] are found in English while there is only [b] in Arabic. Arabic learners are found having difficulty in the pronunciation of it. The difference is of voicing; [p] is a voiceless bilabial plosive while [b] is a voiced bilabial plosive. [p] occurs in all the three positions in English words like; put [pot] at initial position, complete [kəmpli:t] at medial position and tip [trp] at final position.

\section{Bilabial—Nasals}

The consonant [m] is found both in Arabic as well as in English. The point of articulation is lips. It is called as nasal because the basic characteristic of it is that the air escapes through the nose. In nasal consonants, however, air does not pass through the mouth; it is stopped by a complete closure somewhere in the mouth. In this case the soft palate is lowered and the path of nose remained open in the production of it. It is also found in all the three positions in Arabic and English. The examples are: [مكتب] [məktəb] 'office' at initial position, [طماطم] [t'oma:t'əm] 'tomato' at medial position and [كم] [kəm] 'how much' at final position. In English man [mæn] at initial position, campus [kæmpəs] at medial position and come $[\mathrm{k} \wedge \mathbf{m}]$ at final position occurred.

\section{Labiodentals-fricatives}

The lower lip comes in contact with the upper teeth, thus the consonants are referred as labiodentals. For example [f] and [v] are bilabial fricatives but [f] found in Arabic and both [f] and [v] in English. The term fricative is referred because the air escapes through a narrow passage and makes a hissing sound. These are also termed as continuant fricative, because we can continuously produce friction by throwing air outside. [f] is a voiceless consonant while [v] is voiced.

[f] occurs in all three positions of the words in Arabic like; [فريق] [fəri:q] 'team' at initial position, [سفر] [səfər] 'travel' at medial and [خوف] [xəof] 'fear' at final position. This is also so in English like: face [fers] at initial, comfort [kımfət] at medial position and cuff $[\mathrm{k} \Lambda \mathrm{f}]$ at the final position. The consonant [v] also occurs in all three positions in English

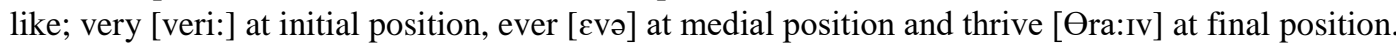

\section{Dental-plosives}

The active articulator is the tip of the tongue and the passive articulator is the upper teeth in the production of dental consonants. The closure in the mouth is released suddenly and air escapes with some explosive noise. These are four in all [ت ] voiceless, [د] voiced, [b] voiceless and [ض] voiced. These all occurs in all the three positions. Examples are:

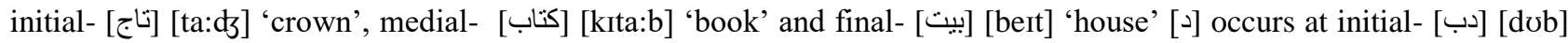

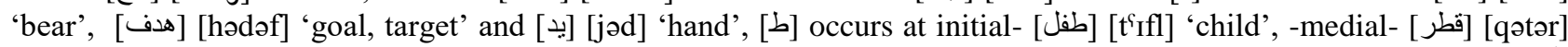

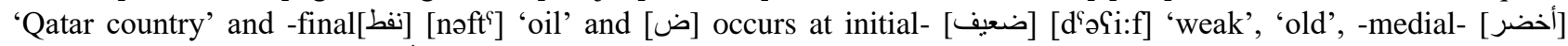
[əxd'ər] 'green' and -final[أرض] [ərd'] 'land', 'ground'.

English has one voiceless [t] and one voiced [d] dental plosives and they occurs all the three positions. [t] occurs at initial- tap [tæp], -medial- stop [stap] and -final pit [pit] while [d] at initial- dog [dog], -medial- model [madl] and final good [god].

\section{Dental-fricatives}

Tip of the tongue comes in contact with lower and upper teeth so these sounds are called dentals. It involves a stricture of close approximation; there is a narrow gap through which air comes with an audible friction and the term given to

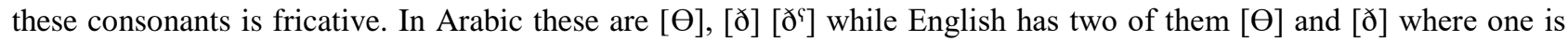

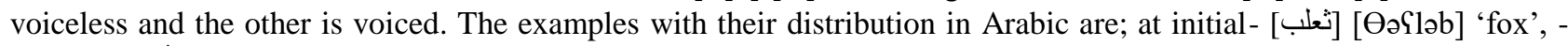

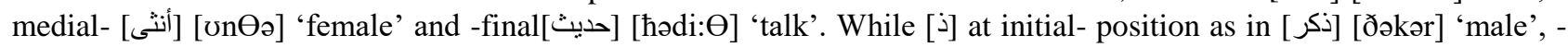

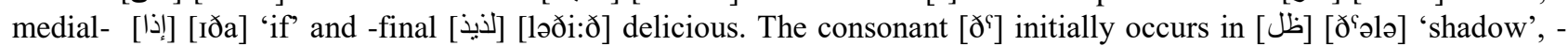

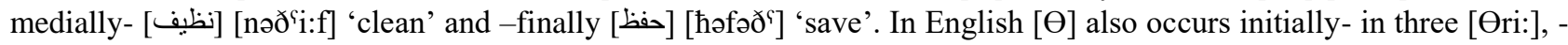
medially- mathematics [mæӨəmætrks] and -finally in tooth [tu: $\Theta]$ and the consonant [ð] in English occurs initially- in

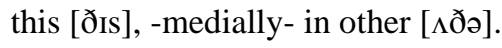

\section{Alveolar-nasal}

In the production of these consonants, the active articulator is the blade or tip of the tongue and the passive articulator is the teeth ridge or alveolar ridge. That is why these consonants are called as alveolar consonants. The air releases through the nose because the soft palate is lowered and the air path to the mouth is blocked, so the term is referred as nasal. This consonant is [n] which is found both in Arabic as well as in English. The examples from Arabic are; 
initially- [نر [nəmr] 'tiger' -medially- [أنت] [əntə] 'you' and -finally [لسان] [lisa:n] 'tongue'. In English it is found at initial position- night [na:It], -medially- connect [kənekt] and -finally gone [go:n].

\section{Alveolar-fricatives}

The tongue comes in contact with alveolar ridge and air escapes with friction through a narrow gap from the oral cavity. In Arabic these are [s] voiceless, [z] voiced and [s'] voiceless but in English [s] and [z], voiced and unvoiced, are found.

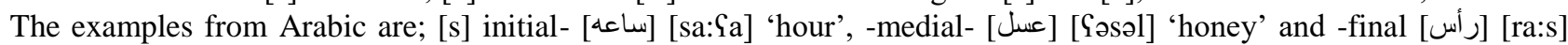
'head', [z] initial- [زرافـ] [zəra:fah] 'giraffe' -medial- [وزير] [wəzi:r] 'minister' and -final [موز] [moz] 'banana'. [s']

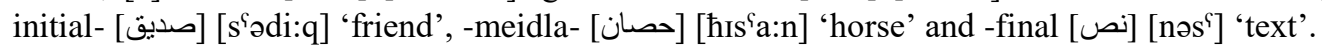

From English, examples include [s] at initial- spice [spa:Is], -medial- disagree [disəgri:] and at -final position ice [a:Is]. The alveolar fricative [z] occurs at initial- in zoo [zu:], -medial- design [dıza:In] and at -final position please [pli:z].

\section{Alveolar-tap}

The tongue touches the alveolar ridge and in the production of a tap, tongue moves towards alveolar ridge, makes a momentary contact, and immediately withdraws to its position of rest. The consonant produced is alveolar-tap [ $\lrcorner$ ] in Arabic and [r] in English. The examples of this consonant in Arabic are; initially- [ربي] [rəbi:؟] 'spring', -medially[برق] [bərq] 'lightning' and -finally [صغير] [s'əyi:r] 'small'. In English it occurs initially- in risk [rrsk], -medially- harm [ha:rm] and -finally matter [mætər]. The [r] sound often found in British English when the letter $r$ occurs between vowels as in very (Sethi \& Dhamija, 2010).

\section{Alveolar-lateral}

The tongue touches alveolar ridge, it involves a stricture of partial closure. There is a partial at some point in the mouth, so that the airstream can escape on one or both sides of the contact. There is a contact between the tip of the tongue and the centre of the teeth ridge; but there is no such contact, at least on one side, between the rim of the tongue and the upper side teeth. The consonant [1] found in all three positions in Arabic; at initial- position [لحم] [ləћm] 'meat',

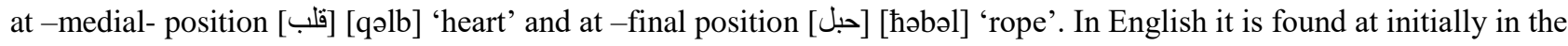
word like lie [la:I], -medially- only [oonli:] and -finally in kill [kıt].

It should be noted that the realization of [1] in the word lie is different from the realization of [1] in the word kill. The sound in lie is what we called a 'clear l' while the sound in kill is what we called a 'dark l'. The phonetic symbol for this sound is [1].

\section{Palatal—affricate}

The front of the tongue comes in contact with hard palate of the roof of the mouth, so the sounds are produced with this obstruction called palatal. The production of affricates is similar to that of plosives. There are three stages called; closing, compression and release. But, the release is sudden in case of plosives while it is gradual in production of affricates. The closure part of the affricate is represented by a plosive, and the release part, fricative is produced at the same point. Thus, the affricate is represented by two letters used in phonetic transcription.

There are two affricates in English those are voiceless palatal-alveolar affricate [ $\mathrm{t}]$ ] and voiced palatal-alveolar affricate [d3] while Arabic has only one that is voiced palatal-alveolar affricate [?] [dz].

In Arabic [d3] occurs in all the three positions in words like; at initial position [جنوب] [dzonu:b] 'south', at -medialposition [شجرة] [علاج]] [Sila:d3] 'treatment'. The voiceless palatal-alveolar

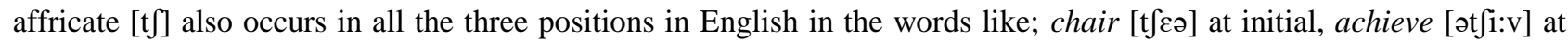
medial and march [matf] at final position. The voiced palatal-alveolar affricate also occurs in all the three position in words of English like; jump [dz^mp] at initial position, soldier [səoldzə] at medial position and village [vilıd3] at final position.

\section{Palatal—approximant}

The front of the tongue comes close to the hard palate, the roof of the mouth. But, the tongue is not as close to the roof of the mouth as in case of fricatives. In this case the narrowing is of a lesser degree. The articulators do not come so close together so that no audible friction is there in the production of this sound. This sound is also referred as frictionless continuant and more often called approximant. The sound is [j] in English and [ي] in Arabic. It is also called a semi-vowel, which is essentially very short approximant. It is very rapid glide towards, or from, a vowel of greater stable duration. It differs from both approximants and vowels in that it is momentary in nature, and cannot be lengthened (Sethi \& Dhamija, 2010).

[j] sound occurs at initial and medial position only, it doesn't occur at final position both in Arabic as well in English. The examples are; [j] at initial position [يد] [jəd] 'hand', at medial position [جيد] [dzərjəd] 'good'. In English it is found in words like; yes [jes] initially and lawyer [lo:jər].

\section{Velar-plosive}

The active articulator, back of the tongue, comes in contact with passive articulator soft palate or velum and produce obstruction in the production of these sounds, so they are called as velar consonants. The air which is blocked at some point in the oral cavity, releases suddenly with some explosive noise and we hear a plosive consonant. Arabic has one velar-plosive that is [⿶] [k] which is voiceless. But, English has one more sound which voiced in nature that is [g]. 
The examples from Arabic are; [كبير] [kəbi:r] 'big, large' at initial position, [حكومة] [hoku:mah] 'government' at medial position and [ملك] [məlik] 'king' at final position. In English it occurs word initially in cool [ku:l], word medially in maker [merkər] and word finally in bake [berk]. The voiced velar-plosive [g] occur word initially in good [god], word medially bigger [bigə] and word finally in $m u g[\mathrm{~m} \wedge \mathrm{g}]$.

\section{Uvular-plosive}

The active articulator, back of the tongue, comes in contact with passive articulator uvula and produce obstruction in the production of this sound, so it is called as uvular consonant. The air releases with an explosive noise and the term is referred to it is plosive. Uvular plosive [ق] [q] is not found in English but it is common sound in Arabic and found in all

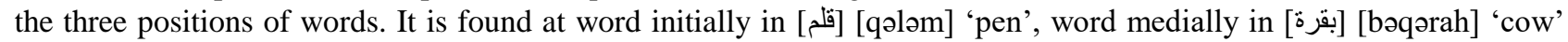
and word finally in [طريق] [t'ori:q] 'road'.

\section{Uvular-fricative}

In the production of these sounds the active articulator, back of the tongue, comes in contact with the passive articulator uvula, but the air escapes with friction, so the term is referred to them is uvular-fricative. These are also not found in English but very natural in Arabic. These sounds are voiceless $[\dot{\zeta}][\mathrm{x}]$ and voiced $[\dot{\xi}][\gamma]$ in Arabic. The voiceless uvular-fricative [x] occurs at word initially in [خبز] [xubuz] 'bread', word medially in [ختلف] [moxtəlif] 'different' and word finally in [ نسخ [nəsəx] 'copy'. The voiced uvular-fricative also occurs at word initially in [غاز] [ya:s] 'gas', word medially in [بغل] [jəyssal] 'wash' and word finally in [فراغ [fira:y] 'empty'.

\section{Pharyngeal—fricative}

With regard to the point of articulation, this consonant is articulated with the tongue root against the back of the throat (the pharynx), thus known as pharyngeal. Its manner of articulation is fricative, which means it is produced by constricting air flow through a narrow channel at the place of articulation, causing turbulence. This pharyngeal fricative is voiceless and found in Arabic but not in English, which is [₹] [ћ]. It occurs in all the three positions in Arabic words.

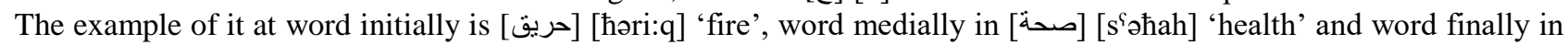
[تفاح] [toffəh] 'apple'.

\section{Pharyngeal—frictionless continuant}

Its manner of articulation varies between approximant and fricative, which means it is produced by narrowing the vocal tract at the place of articulation, but generally not enough to produce much turbulence in the airstream. The place of articulation of this consonant is pharyngeal, which means it is articulated with the tongue root against the back of the throat (the pharynx). It not found in English but natural in Arabic. The letter in Arabic is $[\tau]$ and the phonetic symbol of it is [G]. It is found in all the three positions in Arabic words as in [علم] [Gılm] 'knowledge' word initially,[معلم] [moৎəllım] 'teacher' word medially and [سمع] [səməS] 'hear' word finally.

\section{Glottal-plosive}

The glottal plosive is produced by obstructing airflow in the vocal tract or the glottis. This consonant is plosive because the air is stopped entirely at some point and released suddenly. It is found in all the three positions in Arabic words like; word initially in [أب] [?əb] 'father', word medially in [فئُ] [fIPə] 'category' and word finally in [سماء] [səma?] 'sky'. In English, the glottal stop is represented, for example, by the hyphen in uh-oh!. For most United States English speakers, a glottal stop is used as an allophone of /t/ between a vowel and a syllabic "n", as in button ['be?n] except when talking slowly.

\section{Glottal-fricative}

The articulators for the glottal sounds are the vocal cords. This type of sound is produced by an obstruction, or a narrowing causing friction, but not by vibration between the vocal cords. Thus the air escapes from the lungs with an audible friction through a narrow glottis. The soft palate in this case is raised. This consonant is found in Arabic represented by [0] and in English by [h]. The phonetic symbol for this sound is [h]. It is found in all the three positions in Arabic words like; [هاتف] [ha:təf] 'phone' at initial position, [نهر] [nəhər] 'river' at medial [وجه] [wədzəh] 'face' at final position. In English it occurs at initial position as in half [ha:f] and at medial position in behave [brherv]. It does not occur word finally.

\section{Labiovelar-approximant}

In the production of this consonant the back part of the tongue is raised toward the velum while rounding the lips. it is produced by narrowing the vocal tract at the place of articulation, but not enough to produce a turbulence.

The type of approximant is glide or semivowel. The term glide emphasizes the characteristic of movement (or 'glide') of [w] from the [u] vowel position to a following vowel position. It found in all the three positions in Arabic like; [وزن] [wəzən] 'weight' at word initially, [دواء] [dəwə?] 'medicine' and word finally in [هو] [howə] 'he'. In English it occurs at word initially in west [west] and word medially in sweet [swi:t]. It does not occur word finally.

\section{Recommendations}

1. The correct pattern of word accent in English should be maintained in EFL courses.

2. The consonant $/ \mathrm{p} /$ which is missing in the Arabic phonic system should be acquired.

3. The correct pattern of stress and rhythm in English should be taught to the EFL learners to the exclusion of the typical Arabic pattern. 
4. The voiceless plosives $/ \mathrm{p} /, / \mathrm{t} /, / \mathrm{k} /$ should be aspirated when occurring at the word initial stage to bring the learners' speech production closer to that of the native speakers.

5. The correct distribution of English consonants and vowels should be encouraged in th learners by the use of a pronouncing dictionary.

6. Learners should be given ample practice in pronunciation of the vowel sounds which are invariably replaces by diphthongs (a characteristic they superimpose from the mother tongue).

\section{Conclusion}

It is obvious that the language as a medium of communication plays an important part in our life and this cannot be overlooked. Language learning starts with the sound system of a language. As discussed earlier in this paper, language is an essential asset to human beings in which speech is primary. It is necessary for the language learners to be trained the way by which Arabic and English sounds are pronounced with accurate consideration to their places and manner of articulation. It is with this aim that the similarities and dissimilarities between Arabic and English consonantal sounds have been elaborated to mark the problems faced by the EFL learners in Saudi Arabia. The teachers can prepare the remedial help for the English learners to get over the problem of pronunciation. However, language learning, and specifically foreign language learning, is a long process that requires continuous and comprehensive training and evaluation of both the teachers and learners. With this presumption as the starting point, pedagogical changes followed by in and pre service training of EFL teaching community can go a long way to ensure desirable outcomes for the learners.

\section{References}

Adetunji, B., Waheed, R.O. (2010). Phonetic and Phonology in Comparative analysis of Arabic and English Language. Nigerian Journal of Research and Production 17(2).

Al-Hattami, A.A. (2010). A Phonetic and Phonological Study of the Consonants of English and Arabic. Language in India, 10.

Al-Saqqaf, A.H., Vaddapalli, M.K. (2012). Teaching English Vowels to Arab Students: A Search for A Model and Pedagogical Implications. International Journal of Educational Science and Research, 2.

Cannor, J.D.O. (1967). Better English pronunciation. New York: Cambridge University Press.

Ekundare F. (1993). Phonetics: An introductory handbook. Ibadan: Commercial Printing Works.

Ramamurthi, L. (2004). A History of English Language and Elements of Phonetics. Chennai: Macmillan India Limited.

Roach, P. (2009). English Phonetics and Phonology: A Practical Course. Cambridge: Cambridge University Press.

Sethi, J., Dhamija, P.V. (2010). A Course in Phonetics and Spoken English. New Delhi: PHI Learning Pvt. Ltd.

Simpon J.M. (1972). Notes on phonology: Ordinary class in linguistics and Phonetics, Scotland: University of Glasgrow Press.

Syal, P., Jindal, D.V. (2013). An Introduction to Linguistics. New Delhi: PHI Learning Pvt. Ltd

Varshney, R L. (1995). An Introductory Textbook of Linguistics and Phonetics. Bareilly: Student Store 